\title{
ALGUNOS APARTES DE LA TRADUCCIÓN JURÍDICA Y OFICIAL EN COLOMBIA
}

\section{SOME THOUGHTS ABOUT LEGAL AND OFFICIAL TRANSLATION IN}

FECHA DE RECEPCIÓN: 14 de enero FECHA DE APROBACIÓN:10 de marzo Pp. 58-67

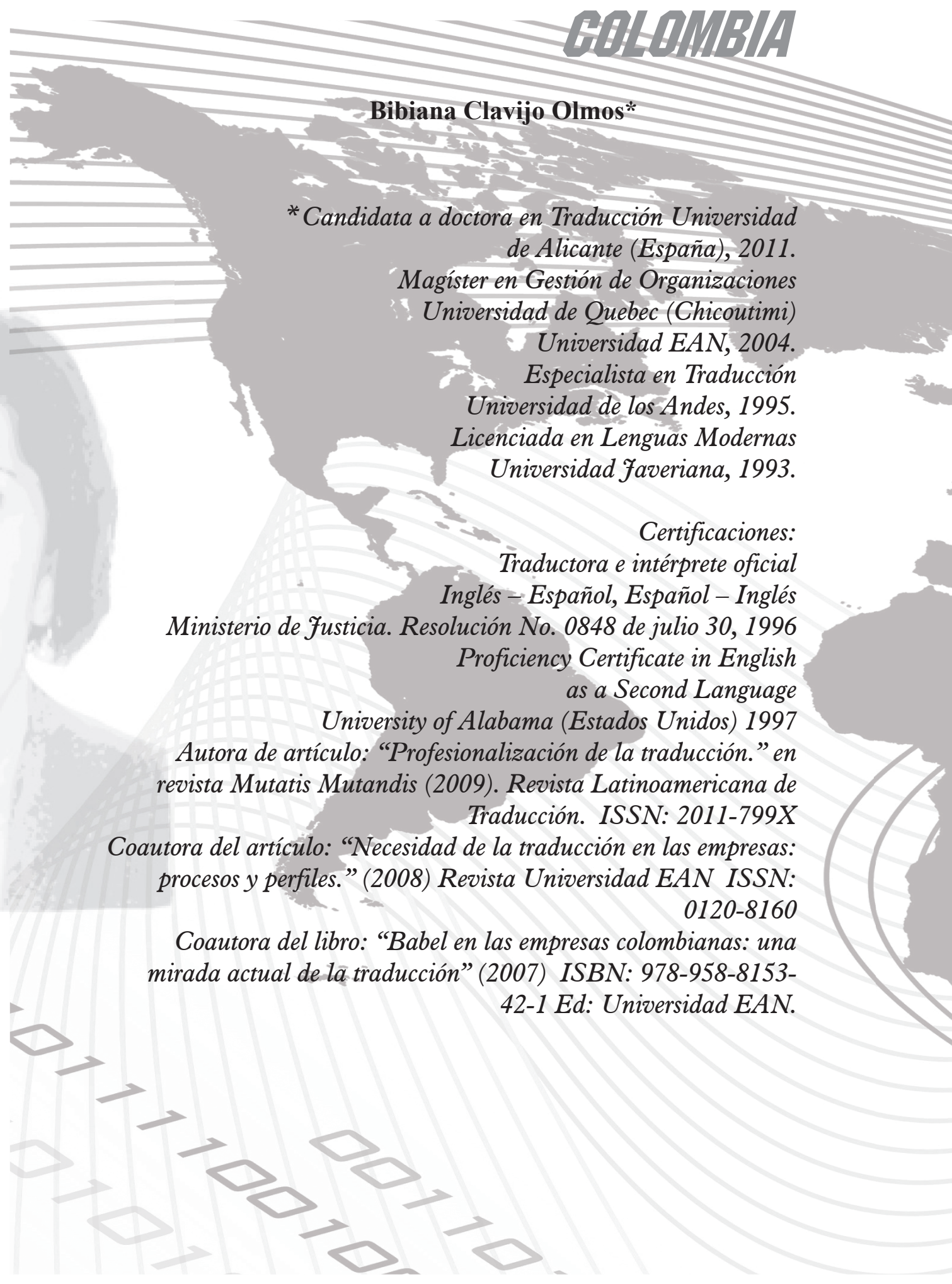




\section{RESUMEN}

La traducción jurídica tiene gran demanda hoy en día, especialmente por la apertura de los mercados y por asuntos de cooperación internacional, como lo afirma Borja (2007). Ante esta necesidad inmediata, ¿Estamos los traductores colombianos preparados para satisfacer la demanda del mercado local y competir en el mercado global? ¿Tenemos las competencias necesarias para hacer traducciones en este lenguaje de especialidad?

Este artículo parte de una base teórica sobre traducción jurídica que incluye un análisis de competencias del traductor de este lenguaje especializado, para posteriormente contrastar la teoría con la realidad del gremio en Colombia y con la certificación actual de traductor oficial. El propósito final del artículo es analizar la necesidad real de formación de traductores jurídicos, de acuerdo con la demanda actual.

\section{ABSTRACT}

Nowadays, there is a growing demand for legal translation due to aspects such as the opening of markets and foreign relations, as stated by Anabel Borja (2007). Are Colombian translators prepared
to satisfy the local market needs and to compete globally? Are they competent enough to translate markets and foreign relations, as stated by Anabel Borja (2007). Are Colombian translators prepared
to satisfy the local market needs and to compete globally? Are they competent enough to translate this language for specific purposes? This article has a theoretical background about legal translation that includes an analysis of the competencies a legal translator should have. It contrasts theory with the real practice of translation and with the Colombian official certificate of translators. The main purpose of this article is to analyze the real need of developing competencies as legal translators by following formal education Programs, in order to supply the market needs. $\rightarrow$ Palabras claves

Traducción jurídica Competencias

Lenguaje de especialidad

Formación

Certificación.
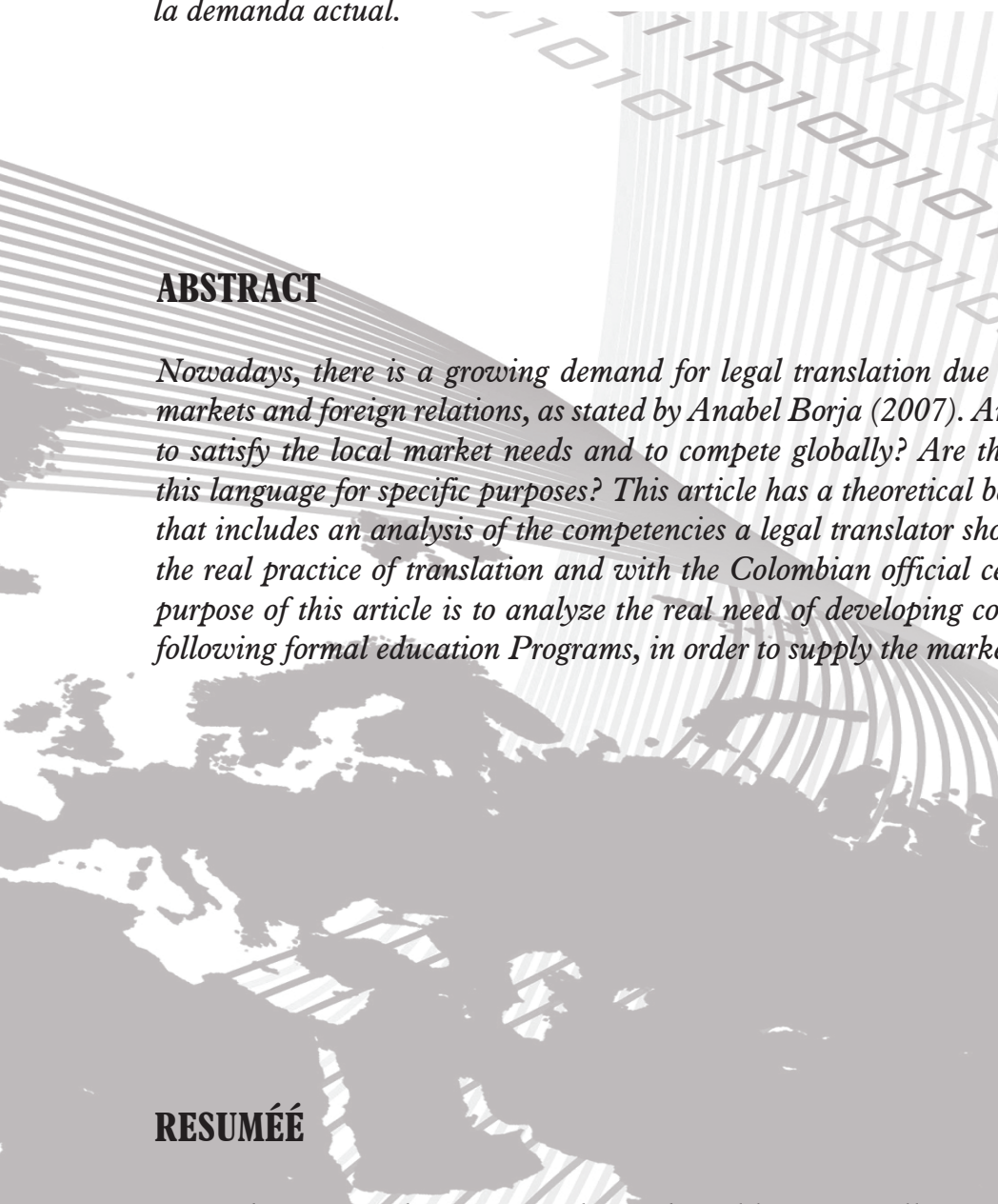

La traduction juridique est très demandée à l'heure actuelle, principalement du fait de l'ouverture des marchés et de la coopération internationale, comme l'a déclaré Anabel Borja (2007). Face à ce. besoin immédiat, les traducteurs colombiens sont-ils prêts à répondre à la demande du marché local et sont-ils compétitifs sur le marché mondial ? Ont-ils les compétences nécessaires pour réaliser des traductions dans ce langage spécialisé?

Cet article s'appuie sur une base théorique de la traduction juridique qui comprend une analyse des compétences du traducteur dans ce langage spécialisé, puis contraste avec la réalité colombienne et avec la certification actuelle des traducteurs officiels. L'objectif sous-jacent de l'article est d'analyser le besoin réel de traducteurs juridiques de formation, conformément à la demande actuelle. 


\section{INTRODUCcIón}

ste artículo es una revisión crítica de lo que significa ser traductor de lenguaje jurídico en Colombia, a la luz de una base teórica creada a partir del análisis de varios autores expertos en el tema. Describe las competencias que debe tener todo traductor y se concentra en las subcompetencias del traductor jurídico, para contrastar lo que significa ser traductor jurídico con la certificación de traductor oficial en Colombia. El fin último es el análisis de la necesidad de desarrollar programas de educación formal de traducción en lenguajes especializados como el jurídico, para poder llegar a certificar a estos traductores por medio de exámenes como el que existe para los traductores oficiales.

\section{TRADUCCIÓN JURÍDICA: DEFINICIÓN Y DEMANDA}

Bomenzaremos por determinar el significado de lo que es traducción jurídica, con base en la definición de dos autores. Mayoral (2002), la define como:

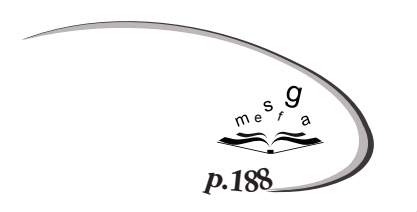

“...la que se inscribe en una situación jurídica o como la que traduce textos jurídicos o textos con elevado contenido jurídico". En cualquier caso, hay un sinnúmero de textos que contienen lenguaje jurídico o cumplen propósitos jurídicos, que en ocasiones no son documentos especializados. Este autor considera que la traducción jurídica es un campo extremadamente difícil de definir por su gran extensión.

Por otro lado, Borja (2007) la define como: “...la traslación de una lengua a otra de los textos que se utilizan en las relaciones entre el poder público y el ciudadano (por ejemplo: denuncias, querellas, exhortos, citaciones, leyes) y también, naturalmente, de los textos empleados para regular las relaciones entre particulares con transcendencia jurídica (que dan lugar a contratos, testamentos o poderes)". Esta segunda definición, que es más específica, sólo hace referencia a la función del texto original dejando de lado la función jurídica que puede cumplir el texto de llegada en una situación específica. A partir de las definiciones anteriores, se puede afirmar que el traductor jurídico se encarga de textos con alto contenido de lenguaje especializado en ámbito jurídico, que además de dominar el género ${ }^{1}$ que traduce, debe conocer la función del texto y las implicaciones de la traducción que realiza.

\footnotetext{
${ }^{1}$ Según Swales citado por García, 2007, un género comprende una clase de eventos comunicativos, cuyos miembros comparten un conjunto de propósitos comunicativos.
} 
Este tipo de traducción especializada, adquiere cada vez mayor demanda por su importancia creciente en la globalización de los negocios y en aspectos de cooperación internacional (Borja, 2007).

Colombia no es ajena a este hecho; por citar un ejemplo, a partir del 6 de febrero de 2011 la corte constitucional de Colombia publica información sobre sus sentencias en español e inglés, debido a la alta consulta que tienen en todo el mundo ${ }^{2}$. Algunos casos específicos de documentos que requieren traducción jurídica son los tratados económicos y políticos que requieren traducción para su celebración, al igual que los contratos y acuerdos comerciales entre empresas. “...la traslación de una lengua a otra de los textos que se utilizan en las relaciones entre el poder público y el ciudadano (por ejemplo: denuncias, querellas, exhortos, citaciones, leyes) y también, naturalmente, de los textos empleados para regular las relaciones entre particulares con transcendencia jurídica (que dan lugar a contratos, testamentos o poderes)"
Otro caso muy común se refiere a documentos derivados de la movilidad entre pueblos, específicamente documentos civiles, eclesiásticos y académicos generados por situaciones de cooperación

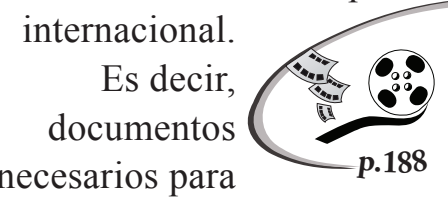

la celebración de matrimonios, obtención de nacionalidad y hasta repartición de herencias. En todos los casos anteriores, las implicaciones de una mala traducción tienen efectos irreparables, razón por la cual se requiere un traductor experto, que sea realmente competente y conozca plenamente su especialidad.

\section{。 \\ 3. COMPETENCIA DEL TRADUCTOR JURÍDICO}

A 1 hablar de competencia traductora, es necesario comenzar por diferenciarla de la competencia lingüística, ya que se estudia la traducción como proceso cognitivo

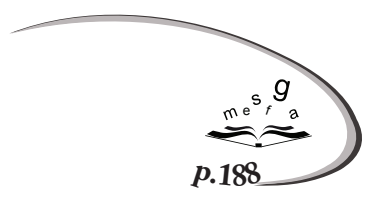

(la mente del traductor) y no como producto (el texto traducido). Para este fin, se hace necesario mencionar el modelo dinámico de adquisición de la competencia traductora del grupo $\mathrm{PACTE}^{3}$, para centrarnos posteriormente en las competencias del traductor jurídico.
Como se observa en la siguiente figura 1, para PACTE la competencia traductora se puede entender como: “... la interrelación de un conjunto de seis subcompetencias conrelaciones, jerarquías y variaciones, donde la subcompetencia estratégica ocupa un lugar central."(Hurtado, 2001: 397). No son las subcompetencias individuales las que definen el perfil del traductor, sino la combinación de las mismas y sólo una de ellas se refiere al aspecto lingüístico y comunicativo.

\footnotetext{
${ }^{2}$ Carta del presidente de la Corte Constitucional e información de Sentencias publicada en http://english.corteconstitucional.gov.co/.

${ }^{3}$ Grupo de investigación de la Universidad Autónoma de Barcelona dirigido por Amparo Hurtado Albir.
} 
FIGURA 1. Modelo holístico de la competencia traductora

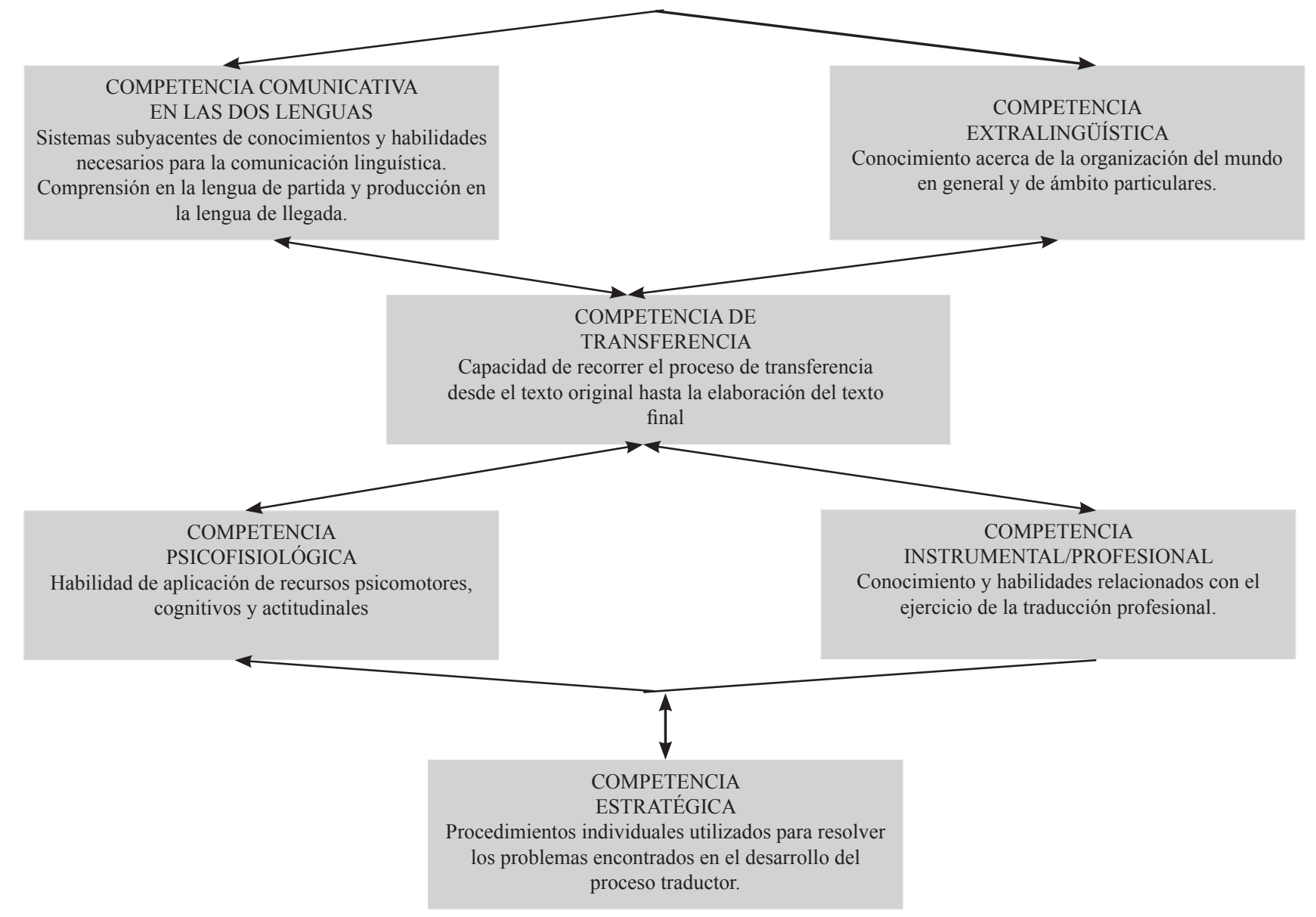

Fuente. Hurtado (2011)

En el caso del traductor jurídico, hay dos subcompetencias que pueden tener mayor relevancia que las demás, al buscar cada vez más especialización y profesionalización en el traductor de documentos de este género de especialidad ${ }^{4}$. Estas son la competencia extralingüística y la de transferencia (Borja, 2005). Con relación a la extralingüística, en esta especialidad más que en cualquier otra, el conocimiento enciclopédico debe ser parte de la formación del traductor, al igual que el conocimiento temático. Como se muestra en la figura 2, el traductor jurídico debe tener además de conocimiento traductológico, conocimiento de cultura general, y de derecho en contextos específicos y comparados; de esta forma podrá lograr transmitir los mismos conceptos y lograr los mismos efectos jurídicos del original. Es decir, para transmitir la misma función del texto original con criterios de precisión y fidelidad.

\footnotetext{
${ }^{4}$ Género jurídico: definido por Borja (2007) como textos con contenidos, retórica y manera de exponer hechos del ámbito jurídico con función comunicativa específica.
} 
FIGURA 2. Competencia extralingüística para la traducción jurídica

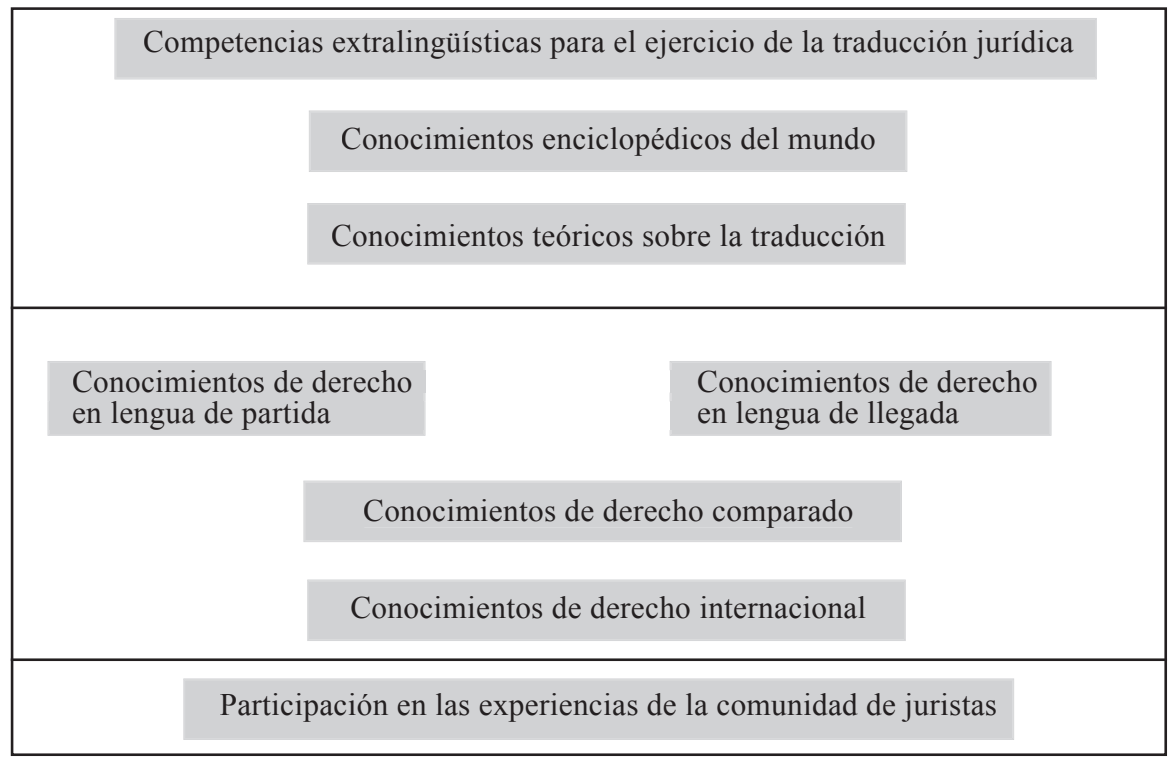

Fuente. Borja (2005)

La subcompetencia de transferencia tiene su relevancia al hacer referencia a la capacidad de comprensión y reexpresión de textos según su finalidad y destinatario, como se evidencia en la figura 3. Aquí se presentan como conocimientos esenciales los tipos de textos tanto en lengua de partida como en lengua de llegada, con el fin de conocer sus características propias y tomar las decisiones correctas al momento de hacer su comparación y posterior traducción. Se habla también del conocimiento de los ordenamientos o sistemas jurídicos y su correlación, con el fin de poder transmitir los conceptos del original. Finalmente, se incluyen varios aspectos comunes de los géneros jurídicos como la macroestructura, aspectos estilísticos, fraseológicos y terminológicos que ayudan al traductor a comprender el original y reproducir el sentido en su traducción con fidelidad y precisión.

FIGURA 3. Competencia de transferencia para la traducción jurídica

\begin{tabular}{|c|c|}
\hline \multicolumn{2}{|c|}{ Competencias textuales para el ejercicio de la traducción jurídica } \\
\hline $\begin{array}{l}\text { Conocimientos de la } \\
\text { tipología de textos } \\
\text { en lengua de partida }\end{array}$ & $\begin{array}{l}\text { Conocimientos de la } \\
\text { tipología de textos } \\
\text { en lengua de llegada }\end{array}$ \\
\hline \multicolumn{2}{|c|}{$\begin{array}{l}\text { Conocimientos de textología } \\
\text { jurídica comparada }\end{array}$} \\
\hline $\begin{array}{c}\text { Aspectos formales exigidos por } \\
\text { la legislación en cada ordenamiento } \\
\text { jurídico }\end{array}$ & $\begin{array}{c}\text { Función y eficacia de los géneros en } \\
\text { géneros en cada ordenamiento } \\
\text { jurídico }\end{array}$ \\
\hline $\begin{array}{l}\text { Macroestructura de los distintos } \\
\text { géneros }\end{array}$ & $\begin{array}{l}\text { Aspectos formales y estilísticos de } \\
\text { los géneros }\end{array}$ \\
\hline $\begin{array}{l}\text { Fraseología característica de cada } \\
\text { tipo de texto }\end{array}$ & $\begin{array}{l}\text { Terminología propia de cada } \\
\text { género }\end{array}$ \\
\hline
\end{tabular}

Fuente. Borja (2005) 
A partir de las competencias mencionadas anteriormente, se puede hablar de un perfil ideal de traductor jurídico capaz de satisfacer la demanda del mercado local y global con precisión y fidelidad. En contraste, el perfil del traductor actual en Colombia determinado a partir de un estudio realizado por la línea de investigación en Lingüística aplicada y Traducción de la Universidad EAN y descrito en Clavijo (2007), habla de traductores con años de experiencia e incluye competencias comunicativas, textuales y culturales muy desarrolladas al menos en dos lenguas y culturas. Estos traductores tienen debilidades en las competencias tecnológicas y profesionales. En este perfil no se habla de competencias extralingüísticas, ni de transferencia en lenguajes especializados.

Según este mismo estudio, actualmente quien se desempeña como traductor en Colombia es: “... una persona que trabaja desde su oficina para varios "clientes", ya sean personas o empresas que solicitan sus servicios de traducción de texto o de interpretación. No existe un criterio establecido de calidad respecto a su labor. Quienes traducen, han llegado a este oficio más por vocación que por formación”. Clavijo (2007). En síntesis, en Colombia hay traductores que han desarrollado competencias por medio de la experiencia en la práctica de la traducción, más que traductores con competencias adquiridas formalmente. En cuanto a las competencias requeridas por el perfil del traductor de lenguajes especializados, no hay evidencia en el perfil actual. Esto nos lleva a considerar la necesidad de formación de traductores expertos en lenguajes especializados, traductores jóvenes que al no tener experiencia, desarrollen formalmente sus competencias en programas de educación formal.

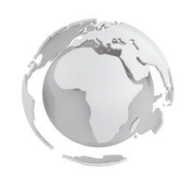

\section{CERTIFICACIÓN DE TRADUCTORES}

La a traducción en Colombia es considerada un oficio con carácter oficial, como auxiliar de la justicia. En el año 1951 Laureano Gómez estableció el oficio de intérprete oficial mediante Decreto 382 de 1951, reglamentado mediante Decreto 2257 de $1951^{5}$. Este Decreto fija como función principal del intérprete: “...la traducción de cualquier idioma al castellano o viceversa, de todos

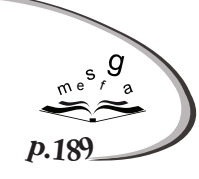
los documentos con mérito oficial ante las autoridades y la interpretación oral en los casos señalados por la ley". Específicamente, este Decreto se refiere a traducción jurídica, según las definiciones presentadas anteriormente.

Según la Asociación Colombiana de Traductores e Intérpretes (ACTI) los traductores oficiales se encargan $\mathrm{de}^{6}$ documentos de carácter civil (registro civil, matrimonio, certificado de defunción, divorcio, entre otros), documentos de carácter eclesiástico (como actas de bautismo y actas de matrimonio), documentos expedidos por juzgados (como sentencias de adopción, por ejemplo), documentos académicos (como diplomas, actas de grado, certificados de calificaciones, entre otros) y documentos expedidos por ministerios, gobernaciones, alcaldías o entidades descentralizadas. Estas traducciones deben ser legalizadas por el Ministerio de Relaciones Exteriores, y apostilladas según el país de donde provengan o a donde se dirijan.

Para certificarse como traductor oficial el Ministerio de Educación, o quien él designe, debe expedir una certificación en los idiomas a actuar, previa presentación de un examen. Actualmente quienes buscan esta acreditación deben presentar un examen de traducción en la Universidad Nacional, que se realiza en dos vías (directa e inversa), tanto oral como escrito con criterios de evaluación muy estrictos. ${ }^{7}$ Según los artículos 251 y 252 del código de Procedimiento Civil de Colombia,

\footnotetext{
5 Tomado del documento "Recopilación de algunas disposiciones de ley que puedan afectar a los traductores en Colombia" compilado por Anthony Letts.

6 Tomado de http://www.traductorescolombia.com/servicios_traduccion\%20oficial.html.

7 Información sobre el examen de traducción e interpretación oficial en http://www.humanas.unal.edu.co/img/Lenguas\%20Extranjeras/Examenestr/Instrucciones\%20 para\%20inscripción\%20diciembre\%202010.pdf
} 
los textos y discursos que se seleccionan son documentos de carácter civil, eclesiástico, o judicial elaborados en Colombia que pueden tener efectos en el exterior (en el caso de traducción inversa) y documentos elaborados en el país de la lengua que se va a certificar, que vaya a tener efectos en Colombia (en el caso de traducción directa). No hay criterios de selección de los candidatos que permitan medir sus competencias iniciales; simplemente deben seguir un proceso de inscripción, que incluye el pago de una suma específica. Como resultado, un pequeño porcentaje de la población que presenta el examen lo aprueba (aproximadamente un 20\% según cifras de los dos últimos años).

Vale la pena analizar si los candidatos a ser acreditados como traductores oficiales deberían cumplir con requisitos previos a la presentación de esta prueba, relacionados con formación o experiencia. Si ellos demostraran sus competencias previas, la certificación sería un equivalente a una tarjeta profesional, que se pueda considerar como garantía de calidad en el servicio que preste este experto.

\section{.}

\section{FORMACIÓN DE TRADUCTORES}

1 continuación se hará una breve descripción de la oferta actual de posgrados en traducción en Colombia, destacando el carácter y contenidos de cada uno de los Programas, con el fin de analizar el aporte que hacen las universidades al fortalecimiento del gremio traductor, poniendo especial énfasis al traductor jurídico.

En Bogotá, está la Universidad del Rosario que ofrece la especialización en Traducción desde 1994. Es un programa de 28 créditos académicos que forma traductores de texto en diversos ámbitos que incluyen periodístico, jurídico, económico, administrativo, humanístico, científico y técnico ${ }^{8}$. Desde el año 2009 la Universidad EAN ofrece la primera Maestría en Traducción con carácter de profesionalización del país, en ámbitos de especialidad. Es un Programa de traducción de textos que se desarrolla en 52 créditos académicos en ámbitos económicos, financieros y de negocios internacionales, que se complementa con ámbitos científicos y técnicos, gracias al convenio de doble titulación con la Universidad Pompeu Fabra de Barcelona, España. En estos dos posgrados se incluye la traducción jurídica en el plan de estudios.

En otras ciudades de Colombia hay cuatro programas de traducción. La Universidad del Valle, que ofrece una especialización en traducción de textos de 30 créditos académicos. Sus contenidos se distribuyen en cuatro áreas: análisis textual y redacción, traducción general y especializada, terminología, documentación e informática y área teórica y de investigación ${ }^{9}$. La Universidad de Antioquia, que ofrece la Especialización en Traducción en Ciencias Literarias y Humanas a partir del año $2004^{10}$. Es un programa de traducción de textos que se desarrolla en 30 créditos académicos. La Universidad Autónoma de Manizales, que ofrece la Maestría en Traducción con carácter investigativo desde el 2009. Es un programa de 52 créditos académicos que estudia el estado actual de la investigación en Traductología y los métodos, técnicas y enfoques existentes ${ }^{11}$. Finalmente, la Universidad de Pamplona ofrece Especialización en Traducción de Texto escrito (español - inglés) que forma traductores con énfasis en texto médico, jurídico, político y de máquinas ${ }^{12}$. Solo uno de estos programas incluye la traducción jurídica en su plan curricular.

A partir de estas breves descripciones se evidencian pocas opciones de preparación de traductores, específicamente en lenguajes especializados y aún menos en ámbitos jurídicos, en contraste con la demanda de sus servicios.

\footnotetext{
8 Tomado de http://www.urosario.edu.co/cienciashumanas/especializaciones/traduccion/Perfiles/

9 Tomado de http://aprendeenlinea.udea.edu.co/revistas/index.php/mutatismutandis/article/viewFile/7/249

10 Tomado de http://docencia.udea.edu.co/postraduccion/index.htm

11 Tomado de http://www.autonoma.edu.co/

12 Tomado de http://200.31.20.155/unipamplona/portalIG/home_22/recursos/general/17022011/escrito.jsp
} 


\section{CONCLUSIONES}

a traducción jurídica requiere traductores con competencias muy específicas, que les permita realizar su labor con estándares de calidad internacional.

Vale la pena preguntarse si es suficiente con buscar certificar la idoneidad de candidatos que no han desarrollado sus competencias como traductores jurídicos, o si la necesidad real es preparar a los traductores en este ámbito de especialidad con el fin de satisfacer la demanda local y competir en el mercado global.

El propósito de los programas de formación en traducción debe ser cada vez más especializado, e ir más allá del desarrollo de competencias lingüísticas y enciclopédicas en ámbitos generales, para centrarse en la traducción en áreas de especialidad, como ocurre en la mayoría de programas que se ofrecen a nivel mundial. Específicamente en el área jurídica, esta formación especializada permitirá llegar a un perfil de traductor con las competencias extralingüísticas $\mathrm{y}$ de transferencia que se mencionaron anteriormente, como elemento clave para satisfacer la demanda actual de traducciones en este ámbito.

La generación de traductores que Colombia necesita requiere educación formal en ámbitos especializados, por la inminente necesidad de traductores de lenguajes especializados como el jurídico, y por el relevo generacional que se requiere en este oficio en Colombia.

Está en las manos de las instituciones formadoras el ofrecer programas de calidad con estándares internacionales que preparen a los profesionales que algún día no muy lejano lleguen a renovar la oferta de la traducción en Colombia con competencias específicas.

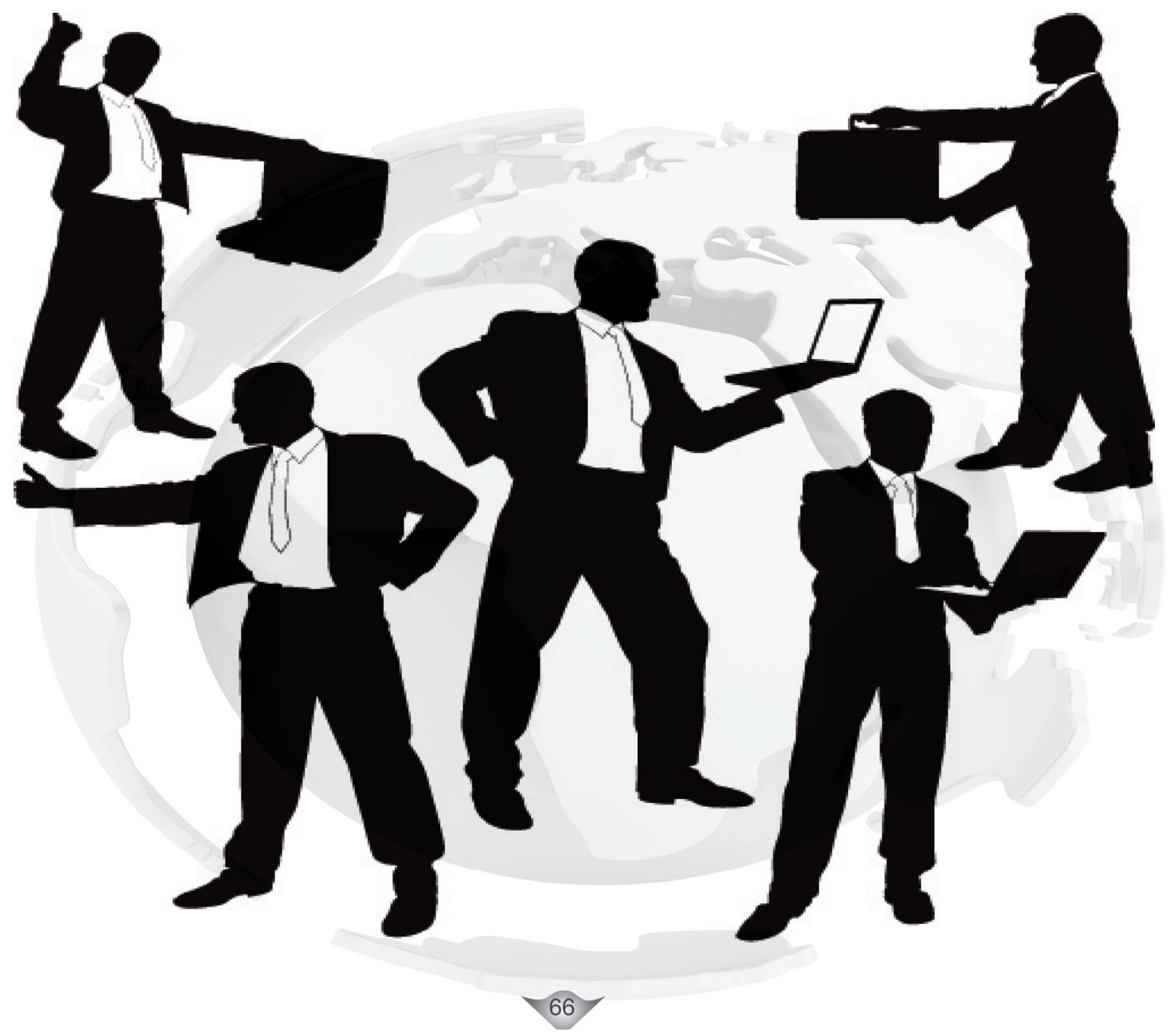




\section{REFERENCIAS BIBLIOGRÁFICAS}

Alcaraz E., Mateo J., Yus F. (2007). Las lenguas profesionales y académicas. Barcelona: Ariel.

Borja, A. (2007) Los géneros jurídicos, en: Alcaráz E. y otros. Las lenguas profesionales y académicas. Editorial Ariel. Barcelona.

Borja, A. (2005) “Organización del conocimiento para la traducción jurídica a través de sistemas expertos basados en el concepto de género textual”, en Isabel García Izquierdo (ed.) El género textual y la traducción. Reflexiones teóricas y aplicaciones pedagógicas, Berna: Peter Lang.

Clavijo et al. (2007) “Babel en las empresas colombianas: Una mirada actual de la traducción” En: Colombia 2008. Ed: Universidad EAN.

García, I. (2007) “Los géneros y las lenguas de especialidad” en Alcaráz y otros. Las lenguas profesionales y académicas. Editorial Ariel. Barcelona.

Hurtado, A. (2001) Traducción y traductología Introducción a la traductología. Editorial Cátedra. Madrid 2001.

Letts, A. "Recopilación de algunas disposiciones de ley que puedan afectar a los traductores en Colombia." Documento sin publicar. Compilado y discutido por el Colegio Colombiano de Traductores a partir del Encuentro Nacional de Traductores Babel VI. 2006.

Mayoral, R. (2002) ¿Cómo se hace la traducción jurídica? Puentes, 2: 9-14 en http://www.ugr.es/ greti/puentes/ puentes $2 / 02$-montaje\%20puentes\%202.pdf 